\title{
Methods and Mechanisms for Mobilizing Users of Social Networks: The Example of Environmental Protests in
} 2019

\author{
Alexander Sokolov ${ }^{1, *}$ Aleksey Belyakov ${ }^{1, a}$ Svetlana Mironova ${ }^{1, b}$
}

\author{
${ }^{1}$ Yaroslavl State University, Yaroslavl, Russia \\ aEmail: belyakov.aleksey920@gmail.com \\ bEmail: s.mironova97@mail.ru \\ *Corresponding author.Email: alex8119@mail.ru
}

\begin{abstract}
The paper considers the theoretical aspects of the formation of protest activity, in particular, reveals the influence of the development of Internet technologies on the transformation of protest forms and tools for involving citizens in virtual activity. In the example cases - environmental protests against the construction of the landfill near the Shies station Arkhangelsk region against the building PPM in Vologda and by applying such methods political analysis as event - analysis index analysis disclosed features of the application user engagement mechanisms social network "Vkontakte" into a virtual protest. Various types of information published on social networks are described: photos, videos, text, a link to an external Internet source. Their effectiveness is evaluated in terms of user involvement in viewing, discussion of the proposed information.
\end{abstract}

Keywords: protest, civic engagement, virtual protest, involvement, involvement mechanisms, mobilization tools, information

\section{INTRODUCTION}

Nowadays, the study of various Internet sites as tools for expressing the opinions of citizens seems important in the context of building communications between civil society and the authorities, which, in particular, is explained by a number of trends. Firstly, due to the constant expansion of the number and functionality of Internet resources, as well as due to the ease of use, social networks become interesting to a wide range of citizens, facilitating their involvement in forms of civic activity. Secondly, the rapid development of the functionality of social networks favors their global distribution among users of all age categories. So, every day more than $58 \%$ of people living on the territory of Russia, browse social networks. According to a study conducted by Mediascope, it is on them that citizens are willing to spend most of their time spent on the Internet. Meanwhile the social network Vkontakte is the most popular among users of all age groups (from 12 to 64 years old) [1].

*Fund: The reported study was funded by the grant from the President of the Russian Federation for state support of young Russian scientists MD-855.2020.6 "Mobilization and demobilization in modern practices of protest activity"
Today, there is a change in the nature of communications, in particular between civil society structures and authorities, as well as the penetration of social networks in all spheres of society. The emerging virtual space, on the one hand, facilitates and accelerates the process of interaction between interested parties, allows to determine the problem field of the region by analyzing user requests and posts. On the other hand, it is the social network that is becoming one of the tools to consolidate a wide range of citizens into civilian activity, including protest activity. Due to their advantages, such Internet sites are increasingly becoming one of the main channels for obtaining information on the activities of state / municipal institutions, a tool for consolidating the population to solve socio-political, economic and other problems, and expressing protest moods.

At the same time, the brightness of the transmitted information, the use of various types of its transmission, as well as the speed of distribution are significant advantages of the social network, are used in the formation of interest groups, increasing involvement of citizens in virtual civic activity.

However, despite the fact that social networks in the political sphere are already quite widely used, there is a need for a detailed study of ways of expressing and 
transmitting information to a wide range of people, as well as in the formation of methodological foundations for studying activities in social networks, which will allow to determine the type of information to view the second promotes the greatest involvement of citizens in the proposed activity.

It is assumed that when implementing protest moods through social networks, citizens most often use a text format for transmitting information, due to the simplicity of its creation, but at the same time, posts containing video or photo information attract the interest of more users.

\section{THEORY}

Throughout all stages of development of the state, citizens have used a variety of tools to express their feelings about the important social and public issues, often couching them in a form of protest.

The protest, as one of the forms of civic activism, which has as its main goal, the solution of significant problems of society by attracting the attention of power structures and the media, is constantly being transformed, using ever new tools to engage and inform more citizens supporting it.

Let us turn to the definitions of protest, which until now, due to the rapid variability of external conditions, have caused controversy among researchers. The literal interpretation of the term characterizes it as a strong objection to something and as a statement of disagreement with any decision, according to the dictionary edited by O.I. Ozhegova and N.U. Shvedova [2]. V.E. Dahl describes the protest as a public expression of his disagreement, a statement of illegality, non-recognition, denial [3].

Numerous foreign and domestic researchers of civic activity (R. Darendorf [4], J. Jenkins, B. Clandermans [5], D. Chelpanova [6], V.V. Safronov [7]) relied on the theory when considering and protesting collective actions and psychological theory, highlighting the following characteristic features: disagreement or objection to the authorities, mass character, dissatisfaction with the uneven distribution of resources in society, the implementation of exclusively active actions of an illegal nature. However, they all do not take into account relatively passive behavior in the implementation of protest moods, for example, deliberate non-participation of citizens in elections, or expressing their position through Internet platforms, viewing and supporting protest posts.

In this regard, in this work, by protest we will understand the form of disagreement directed against a particular object or actor, carried out both in legal and non-conventional forms, encompassed by active and passive actions of protesters and aimed at transforming / changing the structural part society or state [8].

The existence in the state of various forms of expression of protests and their constant transformation are designed to reflect the interests of citizens, to create conditions for the expression of the opinions of the population on a particular issue. So, for example, the traditional forms of protests in Russia are those enshrined in federal law - rallies, demonstrations, pickets, processions, the organization of which is strictly regulated and includes a number of mandatory coordinated actions. "Non-traditional" forms of protests are also developing, characterized by their informal character and brightness - happenings, performances and flashmobs as a reaction of society to the prevailing culture of the modern world, an attempt to attract attention through ridicule, caricature.

The active development of Internet technologies also has an impact on changing forms of protests, there is a "virtual" protest - an innovative form and expression of protest sentiments based on network interactions of citizens and the rapid transfer of necessary information, reactions to emerging problems.

Currently, social networks, conducting thematic groups, publishing in the media information on geography, the time of the rally, and the main goals are one of the main components in organizing the protest rally. Social networks, media begin to play the role of mobilizing the population, quickly disseminating information about the goals and progress of the event, its planning. The main advantages of social networks during the implementation of the protest are:

- speed of communication, the possibility of simultaneous communication of large groups of users online without limiting the number of participants [9];

- the possibility of a relatively accurate assessment of "feedback", i.e. citizen involvement in certain virtual processes through analysis of user actions in social networks (likes, reposts, views) [10];

- the ability to mobilize target groups through association in groups (communities) of interests, which allows you to have an exact impact on a specific target category of citizens [11];

- the use of multimedia technologies that increase user interest in a particular problem, and as a result, involvement in a virtual protest [12].

Thus, the virtual protest - technological forms of civic engagement, implemented, including social networks and performing the role to the anal citizen involvement in protest activities through the use of 
different $x$ mechanism $\mathrm{S}$ PR -technologies and multimedia capabilities of the Internet - a platform.

Using the mechanisms of mobilization of the target groups to participate in protest on social networks has a number of features and is reduced mainly to the publication of various types of information - photos, videos, publications and interactive forms of posts. Writing texts on a social network is the simplest tool for covering an event or problem, based on the literal transfer of content, the objectives of the protest rally, planned actions, etc. Amplification of textual information is served by audio, photo and video files, which visualize the ongoing processes, making the information accessible and understandable to the target audience. Other interactive forms of engagement (a survey, a link to an external Internet source) require certain active actions from the user to obtain more complete information, and may help to form a narrower target audience - those most interested in resolving the problem.

Thus, with the development and widespread dissemination of the Internet, specific forms of protest activity arise and tools for engaging users in protest actions are transformed. The study of activity in social networks $\mathrm{s}$ and effectiveness of the mechanisms involved will identify particular user reactions to different types of information to be published

\section{METHODOLOGY AND EMPIRICAL BASE OF RESEARCH}

The methodology for assessing the effectiveness of mechanisms for involving users of social networks in protest activity is based on tools of political analysis. This line of research provides a fairly wide range of opportunities for studying the socio-political processes taking place in the virtual space. However, it should be noted that the specificity of interpersonal interaction on the Internet imposes some restrictions on the research apparatus, and therefore it is necessary to make a number of changes and significant comments to it. Thus, in the framework of the investigations analyzed two environmental protests in 2019: against the construction of a landfill near a Shies station in Arkhangelsk region and against the construction of a paper mill in the Vologda region.

The protest at the Shies station is an environmental protest, the reason for which was the start of the construction in 2018 of a landfill in a swampy area in the Arkhangelsk region. Explaining the disagreement with the construction of the landfill due to possible pollution of groundwater, a group of local activists held a series of pickets, which, in 2019, developed into an all-Russian format. Over time, the protest at the Shies station has become a symbol of most environmental protests in Russia. During the all 2019 between the protesters and the builders of the landfill was carried out as a real confrontation (clashes and rallies) and information (access to the courts, meetings coverage in social networks). At the time of writing, the protest has subsided, which may be due both to adverse weather conditions for the construction and rallies, and to the decision of the Arbitration Court of the Arkhangelsk Region on the recognition of the construction site at the Shies station as illegal.

The second major environmental protest is related to plans for the construction of a pulp and paper mill on the banks of the Rybinsk reservoir. Concerns about the possible harm to the ecology of the entire Volga water area were expressed by experts and activists immediately from several regions of Russia. Despite the fact that the construction of a new plant in the Vologda region began a long time ago, active protest actions were taken only in the autumn of 2019. At that time, rallies and pickets began to be held in cities, groups were formed in social networks that unite representatives of one particular region as well as users from several regions. A distinctive feature of this protest can be considered its support from the local government, which, according to statements, was in solidarity with the protesters and took measures to cancel the construction. At the moment, this conflict can also be considered abated because the construction of the plant was not approved by both a number of environmental organizations and the Government of the Russian Federation, as stated by Prime Minister Mikhail Mishustin.

The peculiarity of these campaigns is that they all had a kind of representation on social networks - groups aimed at covering these protest campaigns. The VKontakte network was chosen as the main social network, as it is in it that the largest number of users monitor campaigns. The choice of groups depended on the number of subscribers, and the predominance of the protest agenda in publications. As a result, the following became the empirical basis of the study: "STOP PPM" | Yaroslavl Region" [13],"Sudskiy Pulp and Paper Mill - a threat to the Rybinsk airdrome and the Volga River" [14],"WE ARE AGAINST DUMPING ON SHIES" [15]," SHIES" [16].

Publications were highlighted in these groups, the content of which was devoted to the test or the process and topics related to it. So, publications containing advertising materials, publications about the purchase and sale of things, and so on did not fall into the sample. As a result, the selected publications were arranged by publication date from earliest to latest. Subsequently, the analysis was carried out using event analysis. For social networks, this type of analysis has a number of specific features: instead of the media, groups in social networks are analyzed, instead of news posts, the main actors are authors of publications in the 
group (administrators) and users. For actors, the measured values are the number of publications, the number of publications on the topic. On the part of users, the measured values are the number of reactions (likes, reposts, positive and negative comments, number of views) and the number of subscribed users. As a result of the analysis of publications in each group, it is possible to determine both the general activity of actors and subscribers, as well as their dynamics, and dependence on different types of mechanisms used.

However, user activity over a certain period of time cannot be a complete reflection of the effectiveness of the application of various mechanisms for involving users of social networks. In order to determine this indicator, various indices are used, one of which was proposed in the study "Protest Activity on Social Network Sites: A Method of Citizen's Engagement Assessment" [17]. This author's index formed the basis of the methodology used in the described study, but adjustments were made to it to increase the representativeness of the data obtained and to more clearly reflect involvement, taking into account more factors. So, as innovations in the framework of this study, tonality indicators of commentary arias were introduced into the index, reflecting support for the protest or its absence. Positive user comments are a factor that increases engagement, while negative or neutral ones, on the contrary, indicate the absence of an active position of the user in the examined public action on social networks. In addition, in connection with the time frame of the study, it was decided to take them into account on a monthly basis, and not daily, as the initial index, which allowed us to reduce the calculations and make the final indicator more visual. like

Thus, the index formula final modified index looks

$$
W=\frac{L \& 0,63+R * 0,73+K^{+} * 0,73+V * 0,37}{P+F * 0,63+K^{-} * 0,73} / T / 10,
$$

where of $\mathrm{L}$ - likes, the $\mathrm{R}$ - reposts, the $\mathrm{K}+$ - the positive comments, the $\mathrm{V}$ - views, $\mathrm{P}$ - number of posts, the $\mathrm{F}$ - number of subscribers, the $\mathrm{K}$ - number of negative or neutral comments, $\mathrm{T}$ - the number of months of coverage of protest on social networks at the time of the study.

The purpose of this study is to identify the most effective mechanisms for involving users of social networks. In this regard, the index will be applied specifically to various categories of posts, divided into 4 groups: posts containing videos, posts containing a photograph, posts containing text, posts containing an interactive form (test or survey) or a link to an external source, etc. to. it also involves some action from the user. All analysis results are recorded in a matrix showing the total activity for one type of posts within one of three protest actions.

As a result of the application of such a technique, it becomes possible to assess the frequency of use of one or another mechanism in the framework of the protest campaign on social networks, determine the most effective tools, and determine the attitude of users to the information provided by various mechanisms.

\section{RESUlTS}

Investigation of the mechanisms mobilization users of social $\mathrm{x}$ networks protest activity as already described in procedure based on the quantitative indices of their activity, operationalized by methods political analysis. So, the first method used in the analysis of the methods was e vent - analysis, which allowed not only to determine the dynamics of the two environmental campaigns examined in the virtual space, but also became the main one for collecting the necessary empirical data. So, the analysis of the protest against the construction of a landfill in the Arkhangelsk region resulted in the data listed in "Table I".

TABLE I. THE TOTAL ACTIVITY OF THE SHIES

\begin{tabular}{|c|c|c|c|c|c|c|c|c|c|}
\hline $\begin{array}{l}\text { Mechanisms } \\
\text { I number of } \\
\text { publications }\end{array}$ & Likes & Reposts & Views & $\begin{array}{c}\text { Positive } \\
\text { comments }\end{array}$ & $\begin{array}{l}\text { Negative } \\
\text { comments }\end{array}$ & Subscribers & Involvement & $\begin{array}{c}\text { General } \\
\text { reactions }\end{array}$ & $\begin{array}{c}\text { Correlation of } \\
\text { reactions to } \\
\text { posts }\end{array}$ \\
\hline Video $\backslash 83$ & 19113 & 3818 & 1065506 & 1519 & 130 & 17960 & 0.526599855 & 1090086 & 13133.56627 \\
\hline Photo $\backslash 98$ & 20557 & 4115 & 939994 & 1519 & 134 & 17960 & 0.467671996 & 966319 & 9860,397959 \\
\hline Text $\backslash 112$ & 22832 & 4544 & 1079847 & 1650 & 154 & 17960 & 0.518045872 & 1109027 & 9902,026786 \\
\hline Interactive $\backslash 3$ & 654 & 93 & 25568 & 51 & 0 & 17960 & 0.012593689 & 26366 & 8788 \\
\hline
\end{tabular}

From the general results of the protest campaign on social networks, we can see that its organizers relied more on traditional mobilization mechanisms: text materials, as well as photos and videos. Their greatest concentration was noted in the summer months, when directly at the construction site there were clashes between eco-activists, local residents on the one hand, police, and local security on the other. Nevertheless, the ratio of social network users reactions to the posts with each of the types of mechanisms suggests that users are much more active on the reacted to the publication of interactive content: links to external sources, surveys and articles. It follows that the organizers of this campaign did not take this fact into account and did not use the capabilities of social networks effectively to mobilize users. Unusual is also the predominance of 
text materials over others. On the one hand, this is due to the fact that graphic materials are often accompanied by textual ones, supplemented by them. On the other hand, text materials allow a broader description of what is happening, satisfy the curiosity of the target audience, motivate them to participate, which is confirmed by the largest number of reactions from users - 1109027. However, the ratio of reactions to posts does not allow us to say that text materials are the most effective in the process of mobilizing users, this issue will be considered further.

Lack of attention to the interactive content even more noticeable in the mobilization of social network users in the protest action against the construction of a paper mill on the Rybinsk Reservoir: here, within two months of the campaign was published only one post interactive content, but it also showed the highest result by the ratio of posts and reactions (see "Table II").

TABLE II. THE RATIO OF POSTS AND REACTIONS

\begin{tabular}{|c|c|c|c|c|c|c|c|c|c|}
\hline $\begin{array}{c}\text { Mechanisms } \backslash \\
\text { number of } \\
\text { publications }\end{array}$ & Likes & Reposts & Views & $\begin{array}{c}\text { Positive } \\
\text { comments }\end{array}$ & $\begin{array}{l}\text { Negative } \\
\text { comments }\end{array}$ & Subscribers & Involvement & $\begin{array}{c}\text { General } \\
\text { reactions }\end{array}$ & $\begin{array}{c}\text { Correlation } \\
\text { of reactions } \\
\text { to posts } \\
\end{array}$ \\
\hline Video $\backslash 23$ & 1169 & 222 & 71871 & 139 & 39 & 12345 & 0.176222406 & 73440 & 3193.043478 \\
\hline Photo $\backslash 496$ & 10553 & 2372 & 387934 & 815 & 322 & 12345 & 0.940446277 & 401996 & 4187,458333 \\
\hline Text $\backslash 100$ & 11969 & 3188 & 443218 & 984 & 320 & 12345 & 0.730607457 & 459679 & 4596.79 \\
\hline Interactive $\backslash 71$ & 5682 & 1611 & 223944 & 552 & 161 & 12345 & 0.55246834 & 231950 & 3266,901408 \\
\hline
\end{tabular}

From these data also shows that the organizers of the protest action neglected videos, preferring photos from rallies places, as well as photographs pits personalities associated with the protests in the cities on the Volga. An interesting feature of this campaign is the large number of interactive mechanisms used throughout the year of its implementation. However, they are not the most appreciated i.e. In the framework of this campaign, text materials attracted the most attention. Comparing user activity with the previous action, it should be noted that in the framework of protests against the construction of the pulp and paper mill, users were less active than protesters against the construction of the landfill in the Arkhangelsk region. However, user activity does not provide a clear idea of their involvement in the campaign. So, in the framework of this protest action, the highest level of user engagement equal to 0.94 was recorded. This indicator makes it possible to build assumptions that publications containing photographs more often become the subject of evaluation, distribution and commenting by users than other materials. Nevertheless, this assumption is not confirmed by the first considered example with a protest action in Shies, where the most involvement in the protest is provided by materials containing video. The engagement for these publications is 0.52 and does not significantly exceed the engagement for textual materials, equal to 0.51 . It is worth noting that text materials have a high involvement in the campaign against the construction of the pulp and paper mill, equal to 0.73. Based on this, we can make assumptions about the proposed strategies for using various mechanisms for mobilizing users of social networks in the framework of protests and campaigns.

\section{CONCLUSION}

To summarize this study, it is worthwhile to dwell on the issues and possible directions of further scientific research that arose as a result of analysis of the data obtained. So, one of the most complex and important issues from the point of view of the methodology is the ability to take into account many different factors when talking about the effectiveness of using mechanisms for mobilizing users of social networks. This issue is relevant because in the future studies, in order to concretize the result and to be more representative, it is necessary to find ways to operationalize such factors as: environmental influences, the influence of power and the influence of the media, the level of support and the degree of dissemination of information, etc. Taking into account the specifics of this will also make it possible to determine the real relationship users to a particular action and campaign, to the activities of socio-political actors in social networks.

Considering the virtual representation of protests and campaigns, it is worth noting that social networks, indeed, have become one of the main tools for mobilizing, motivating and informational activities, aimed primarily at users of social networks. However, this raises the question of the interdependence of real factors on virtual activity and vice versa. In this case, it can be assumed that the activity of users of social networks positively influenced the decision by the government to cancel the construction of the pulp and paper mill. But, at the same time, the same activity within the framework of the campaign on Shies could distract a number of users from real participation in the protest due to online actions, which, as we know, are less time- and labor-consuming, and the user is less responsible for their commission. 
If we talk about the conclusions based on the direct results of the study, then we can say that the hypothesis was only partially confirmed: the video materials are indeed an effective tool for motivating users, showing the best results in calculating engagement indices. However, interactive materials are not highly effective and their indicators of involvement are medium and low, which may be due to their almost complete absence in one of the protests.

In addition, of interest is the format of textual information as a tool for mobilizing users. Having high levels of engagement and subscribers, this type of material can be recommended for use in the future. It is also worth noting that additional attention should be paid to the study of the dependence of user activity under one post with the text and its length, which can also achieve greater clarity when calculating the effectiveness of mobilizing social network users in the future.

An important aspect of the study of virtual protest is one of its main indicators - user activity and involvement. In the framework of this study, it was possible to establish that these values are inconsistent and vary in their values depending on the influence of two main factors: the activity of the organizers of the virtual protest, the tools they use, and also on the situation around the protest in general, including the real manifestations of activity in in the form of meetings, speeches. So, we can observe an increase in user activity during broadcasts of rallies, or under posts asking to sign a petition, which indicates the interest of users in real events. At the same time, there is a low level of involvement in the processes taking place in the Internet space between real actions - in between meetings and, which can be evidenced by a significantly smaller number of user reactions to posts posted by the organizers that are not related to the main protest topic.

Thus, we can say that in modern conditions, with the current level of development of social networks, they have a wide range of tools that can attract the attention of users, thereby mobilizing them for the manifestation of virtual activity, which can go real. Depending on the choice of these tools and the correct use of external factors, initiators of protest campaigns and actions can significantly increase the coverage of information activities and attract more sympathetic citizens expressing their own civic position in the virtual space.

\section{References}

[1] Social networks in numbers / Mediascop Research Company [electronic resource] URL: https://mediascope.net

[2] S.I. Ozhegov, N.Yu. Shvedova. Explanatory dictionary of the Russian language. 3rd ed., Erased. M.: Az, 1996.
[3] V.I. Dahl. Explanatory dictionary of living Great Russian language. 7th ed. T. 1 - 4. M.: Russian language, 1978

[4] R. Darendorf, [R. Dahrendorf] Modern social conflict. Essay on the policy of freedom [Text] / R. Darendorf. M.: ROSSPEN, 2002. 288 p.

[5] V.V. Kostyushev, V.V. Gorkovenko. Sociological description of collective protest actions: information database of protests (PRODAT - SPb) // Social movements in modern Russia: from a social problem to a collective action. M.: Institute of Sociology of the Russian Academy of Sciences. 1999. pp. 144 177.

[6] D.D. Chelpanov. The nature and dynamics of protest activity in southern Russia: Abstract. dis. cand. social sciences. Novocherkassk, 2011. p. 13.

[7] V.V. Safronov. The potential of protest and the democratic perspective // Journal of Sociology and Social Anthropology. 1998. No. 4. P.117.

[8] A. A. Frolov, S. Mironova. Protest campaigns in modern Russia: a regional aspect on the example of the Yaroslav region. Politbook No. 1. Publisher: Research Institute of Public and Political Sciences (Cheboksary) - 2019. pp. 1-21.

[9] Z. Tufekci, C. Wilson. Social Media and the Decision to Participate in Political Protest: Observations from Tahrir Square // Journal of Communication. 2012. No. 62. pp. 363-379.

[10] J. Curran. Mediations of democracy // Mass Media and Society. New York: Oxford University Press, 2005. pp. 122-149.

[11] C.R. Berger Interpersonal communication // Stacks D.W., Salwen M.B. (Eds.) An integrated approach to communication theory and research. 2nd ed. Mahwah, NJ: Lawrence Erlbaum. 2009. pp. 260-279.

[12] J. Van Laer. Activists 'Online' and 'Offline': The Internet as an Information Channel for Protest Demonstrations // Mobilization. 2010. Vol. 15, No. 3. pp. 405-417.

[13] "STOP PPM»| Yaroslavl Region"/[Electronic resource] URL: https://vk.com/stopcbk_volga(accessed date: 01/13/2020)

[14] "Sudskiy Pulp and Paper Mill - a threat to the Rybinsk Resp. and the Volga River"/ [Electronic resource] URL : https://vk.com/stop_cbk (accessed date: 1/13/2020)

[15] "WE AGAINST DUMPING ON SHIES" / [Electronic resource] URL: https: //vk.com/great_food (accessed: 01/13/2020)

[16] SHIES / [Electronic resource] URL: https://vk.com/ob_kotlas (Date accessed: 01/13/2020)

[17] A. Sokolov, A. Belyakov, A. Frolov. Protest Activity on Social Network Sites: A Method of Citizen's Engagement Assessment In: Chugunov A., Khodachek I., Misnikov Y., Trutnev D. (eds) Electronic Governance and Open Society: Challenges in Eurasia. EGOSE 2019. Communications in Computer and Information Science, vol. 1135. Springer, Cham. 2019. pp. 217 242. 